\title{
Assessment of How House Ownership Shapes Health Outcomes in Urban Ghana
}

\author{
Delali A. Dovie \\ Department of Sociology, University of Ghana, Box LG 65, Legon, Accra, Accra GPO, Ghana; \\ dellsellad@gmail.com
}

Received: 16 March 2019; Accepted: 23 May 2019; Published: 30 May 2019

\begin{abstract}
Background: This study investigates home ownership and its apparent health outcomes in Urban Ghana, utilizing both quantitative and qualitative datasets. Methods: The sample for the study consisted of 442 respondents using a multi-stage sampling technique. Results: The context in which houses are situated affects social support networks, physical and mental health outcomes. House ownership is then a precondition that enables social contact within neighborhoods. A Cramer's V test value of 0.750 suggests a strong association between house ownership and health outcomes. Conclusion: House acquisition and ownership can potentially improve overall physical, and mental health and wellbeing.
\end{abstract}

Keywords: retirement; house; healthcare; pension system; workers; old age

\section{Introduction}

Older adults constitute one of the fastest-growing age categories worldwide. Population aging is occurring at the fastest rate in Low and Middle Income Countries (LMICs) in Africa, Asia, and Latin America. It is estimated that by 2050, approximately $80 \%$ of the world's older population will be found in these countries [1]. Persons aged 65 years and above make up a bigger portion of the population presently, and this group is expected to continue increasing both in absolute and relative terms compared to the remainder of the population. Everyone has the right to live a healthy life, regardless of age, race, creed and color, political or social status. In sub-Saharan Africa, a rapidly aging population is presenting challenges to healthcare systems. Ghana's aging population has increased seven-fold over a 50 year period-from 213,477 to 1,643,381 in 2010 [2]. The current percentage of Ghanaians above 60 years is $6.7 \%$. This is one of the highest proportions of that age category in sub-Saharan Africa [3].

\subsection{Housing Issues in Ghana}

A house is a vital safety need [4], the non-existence of which presents workers with one of the greatest challenges in post-retirement life. House acquisition is "the purchase or securing of a house for use as a residential facility with retirement in focus" [5]. In a study conducted by reference [6] on the topic 'systematic preparation process and resource mobilization towards post-retirement life in urban Ghana: An exploration', it was observed that the indirect financial actions undertaken in preparing for post-retirement life, medical actions (28.13\%) and finding a place of residence to relocate to after retirement (50.63\%) are the most commonly indicated options [6]. Well-established arrangements and structures that are part of the culture of society, for instance, competitive markets, the banking system and a system of property rights are examples of economic institutions.

Economics has made a substantial contribution to our understanding of the law, but the law has also contributed to our understanding of economics. Socio-economic rights have often been regarded as being less enforceable than civil and political rights [7]. The right to adequate housing, 
despite protecting one of the most basic needs of human beings, has not escaped this classification. Despite its strong foundations in international, regional and domestic legislation, many people are still deprived of one or more of the different key elements that comprise adequate housing. The stock of housing in any given society including Ghana encompasses privately owned and occupied houses and apartments, privately rented and local authority rented accommodation, and property managed by housing associations.

The law is a system of rules that are created and enforced through social or governmental institutions to regulate behavior. It has been defined both as 'the science of justice' and 'the art of justice' [8]. It is also a system that regulates and ensures that individuals or a community adhere(s) to the will of the state. The law shapes politics, economics, history and society in various ways and serves as a mediator of relations between people. The national housing policy reflected in Section 12(2) of Ghana's 1992 Constitution states that "Every person in Ghana, whatever their race, place of origin, political opinion, color, religion, creed or gender shall be entitled to fundamental human rights and freedoms of the individual contained in this, but subject to respect for the rights and freedoms of others and for public interest". Section 14 covers protection of the right to personal liberty. Section 17(2) ensures equality and freedom from discrimination on grounds of gender, race, color, ethnic, origin, religion, creed or social or economic status. Section 24 lays down economic rights, including the right to work under satisfactory, safe and healthy conditions and to receive equal pay for equal work. Section 27(1) promotes women's rights, including paid maternity leave. Section 28 covers among other things protection against exposure to physical and moral hazards. Section 36, subsection (10) safeguards the health, safety and welfare of all persons in employment [9].

The Labor Act ensures the protection of working women. It outlines the fact that discrimination results in lower average earnings for women. However, lower average earnings may even be a better indication of discrimination against females, generally, at the household and community levels [10,11].

According to Diamond [12], housing rents are steadily rising in many areas. Rent and the associated controls seem to assist current tenants in the short run. In the long run, it decreases affordability, fuels gentrification, and creates negative spillovers on surrounding neighborhoods. The benefits of rent control are expressed in its provision of insurance against rent increases, potentially limiting displacement. Affordable housing advocates argue that these insurance benefits are valuable to tenants. For example, if long-term tenants have developed neighborhood-specific forms of social capital, such as a network of friends and family, proximity to a job, or children being enrolled in local schools, then tenants face large risks from rent appreciation. In contrast, individuals who have little connection to any specific area can easily insure themselves against local rental price appreciation by moving to a cheaper location.

Some studies, for instance, Diamond et al. [13] examined the consequences of an expansion of rent control on renters, landlords and the housing market in society, showing that small multi-family housing was now primarily owned by large businesses and should face the same rent control as large multi-family housing. Similarly, they examined rent control's effects on tenant migration and neighborhood choices. They found that the beneficiaries of rent control are $19 \%$ less likely to have moved to a new address. These effects are significantly stronger among older households and among households that have already spent a number of years at their address. This is consistent with the fact that both of these populations are likely to be less mobile. Renters who do not need to move very often are more likely to find it worthwhile to remain in their rent controlled apartment for a long time, enabling them to accrue larger rent savings.

The major challenge facing the housing sector in Ghana is the development of a strategy in the short term to address the huge housing deficit, and in the medium to long term, ensure that the citizenry, particularly the low-income sector of the society, are able to access housing either through ownership or rental mediums [14]. Government has a major role to play in the creation of an enabling environment for housing delivery through a variety of initiatives, particularly initiatives targeted at low income groups. 
Housing is a multi-dimensional commodity that includes physical shelter, the related services and infrastructure, and the inputs such as land and finance required to produce and maintain it. Housing also covers solutions geared towards the improvement of shelter and the environment in which it exists. The constraints against Ghana's ability and capacity to resolve the housing crisis are many. On the supply side, the factors encompass land costs and accessibility; lack of access to credit; high costs of building materials; outdated building codes and standards; and lack of effective regulatory and monitoring mechanisms. On the demand side, it is basically affordability in the face of the generally low incomes of the people [14].

"In order to meet the housing challenge in the country, government aims to establish a sustainable housing process which will eventually enable all Ghanaians to secure housing with secure tenure, within a safe and healthy environment and viable communities in a manner that will make a positive contribution to a democratic and integrated society, within the shortest possible time frame". [14], (p. 10)

Housing does not only fulfil the basic need of shelter, but also plays a vital role in the economic health of the nation. Economic growth and prosperity enhance the creation of integrated communities and foster a sense of pride, which could encourage family self-sufficiency. The greater the ability of households in the Ghanaian society to be self-sufficient, the less the anticipated input or responsibility of the government to support that household.

On the macro level, house ownership or the lack of it appears to be a balancing factor for multidimensional frailty. Further, some older people are not able to adapt to (digital) changes in society, which seems to influence their frailty balance in a negative way. The concept of "financial fragility," might be relevant to this, as introduced by Lusardi and Mitchell [15]. Moreover, health literacy seems to be an important macro-level factor. Previous research has shown, especially among older adults, that inadequate health literacy is associated with poorer physical and mental health [16-18].

House ownership may also be experienced in various ways by different individuals, such that while one individual experiences it as an adverse phenomenon, another perceives it as a positive experience. Also, previous research such as Hardy et al. [19] has shown that adverse actions and/or life events are often associated with sudden events such as (personal) illness or death of a loved one [19]. Older adults may enjoy old age when they access essential facilities in society such as adequate food, housing, healthcare [20], and institutional homes among others. The acquisition of a house enables the saving of money that would otherwise be required for renting an apartment in old age. Such money could be channeled into meeting select survival needs [5]. This is a factor in the relatively low levels of pension incomes in Ghana [21].

\subsection{Health Concerns}

Older adults have a myriad of problems with their living conditions, for example, falls in older age are associated with mobility, reduced quality of life, increased notion of admission into long-term care facilities [22], healthcare expenditure(s) [21,22] and premature deaths. Further, a wide range of diseases affect older adults including increased cognitive impairment, Alzheimer's disease, sensory impairment, gait, falls and related medical conditions. Others affect hearing, vision, kidneys and bladder, heart and lungs, or cause diabetes, digestive problems, arthritis, stroke, and dementia [23]. Like individuals, older persons are vulnerable to different other types of chronic diseases and geriatric syndromes such as chronic pain, depression, sleep disorders, pressure ulcers, osteoporosis, and movement disorders [24], while other challenges that older adults are faced with may be physiological, social (including social isolation from (nuclear) family), health, economic and psychological in nature.

\subsection{Pension Policy}

Ghana's pension policy is underpinned by Act 766, which is constituted by three tiers. The introduction of tiers 2 and 3 of the pension scheme extends pension contribution to all workers, 
including those in the informal sector. It also creates an avenue for acquiring a primary residence in particular [25].

Housing is a major problem for many people, especially older people [26]. As such, the older people become, the more essential houses become to them. Hence, "... more needs to be done to meet this most important need" (p. 242). As a consequence, the mortgage facility inherent in the present national pension system comes in at an opportune time, since building affordable houses for workers has become a challenge due to funding from the central government for workers' housing continually shrinking [27].

A variety of housing or residential facilities are available to workers before and after retirement. The before retirement options entail co-housing, shared housing [27], voluntary and private homes, including apartments, detached and semi-detached forms of (low-cost) housing [26,27]. Retirement planning by workers can sometimes be implied through house acquisition and in the absence of flats or houses, old age homes may serve as an alternative for those who lack the former [5]. Some people prefer to live in their own homes and they do not go into a separate residential facility [27]. An aging adult needs to possess a house, though they cannot obtain one [5]. Clearly, using contributed pension funds for a mortgage in acquiring a house is one of the five benefit pillars of the three-tier pension system [28,29].

The essence of retirement planning and the attendant plan diversification [28,29] beyond pension contributions to include house acquisition and ownership, and the means of houses purchasing by workers is imperative. They both may be attained through the process of savings, the most significant fiscal action that fosters financial resource mobilization for home purchases and ownership. Significantly, the new pension system may foster the provision of houses for the lower income category of workers, including informal sector workers [5] (p. 39). However, when government is unable to assist directly, the same purpose may be attained indirectly through the state's pension policy [5], (p. 42). Other means of acquiring houses include gifts, philanthropists and building on incremental basis [5].

As Bloom et al. [30] have underscored, advancements in healthcare and medicine have helped people to live longer and healthier. But, the large masses of older adults encountering difficulties in terms of limited economic resources, mandatory retirement ages, and dilemmas relating to housing issues and changing family structures pose considerable adversities for older persons [30,31].

The growing number of older people is both an opportunity and a challenge for individuals, families, and societies [32]. An increasingly older population poses several challenges for healthcare systems and service delivery because the health characteristics and complexity of care necessary for older adults vary from those required by younger populations, and this population requires a more comprehensive healthcare service system. To attain a healthy lifestyle without any challenges in obtaining healthcare services and family support, home location must be taken into consideration.

\subsection{Power Relations}

A controversial dimension of power pertains to cause and effect relationships, where possible outcomes of certain power moves and/or decisions are not directly traceable or clearly linked. As a result, Barnett and Duvall [33] have observed that "... power works in various forms and has various expressions that cannot be captured by a single formulation." [2] (p. 41). This aspect of power is that which occurs when one individual exercises power over another individual through the process of influencing the latter's wants and interests in favor of the former individual's preferences [32]. The paper sought to answer the following research questions: What are workers' expectations in anticipation of old age in terms of residential arrangements? To what extent do the interests of family relations affect house ownership, location and healthy well-being? What is the association between the ownership of residential facilities and health outcomes? 
The paper is organized as follows: Section 1 introduces the study, Section 2 presents the methodology employed in the study, Section 3 presents study findings, Section 4 discusses the findings and Section 5 concludes the study.

\section{Materials and Methods}

Tema is a typical major Ghanaian city that is privy to and epitomizes an urban setting. It articulates the deepened prong of workers' house ownership and its connection to health and well-being in old age.

The explanatory sequential mixed methods strategy was employed in this study. Using a two-phase approach, the study gathered both qualitative and quantitative data collected between mid-2016 and early 2017. The first phase ascertained workers' specific views on house acquisition and ownership, as well as retirement property and health outcomes. As a result, the quantitative data explored the following hypothesis: There is an association between house acquisition and ownership, and relatively sound health and/or well-being. The second qualitative phase sought to understand the lived experiences of the participants regarding their house acquisition and ownership and the related health outcomes.

\subsection{Sample Selection and Size}

A multi-stage clustered sampling technique was used to select a sample of 442 workers aged 18-59 years utilizing the formula developed by Moore and McCabe [34]. An anticipated non-response was built into the survey design. In which case, the total population of Tema according to Ghana Statistical Service [35] is 292,772 , out of which 135,640 are employed, and it was from this group that the sample for the study was selected.

For the qualitative phase, 5 people aged between 50-59 (i.e., late middle-aged) who participated in the first phase took part in the qualitative phase of the study with the purpose of obtaining an explanation for issues raised in the earlier phase. Also, 5 retirees were selected purposely due to their retired status, who also participated in the study. In all, there were 10 participants who participated in the study's qualitative phase.

\subsection{Research Instruments}

A questionnaire containing two sections was used in the process of data collection. Section 1 was on the socio-demographic characteristics namely age, educational level, and ethnicity. Section 2 explored issues of retirement aspirations, house acquisition and ownership. The questionnaire was created based on previous research, input from colleagues and also the study's research interests. Examples of questions that have been previously used in published studies include questions about housing issues [5,36]. After the initial questionnaire was written, qualified experts reviewed it, especially for grammatical corrections and accuracy. Before conducting a pilot of the questionnaire on the intended respondents, it was tested on a small sample of 30 individuals following the guidelines of Perneger et al. [37]. Afterwards, a pilot test among the intended respondents for initial validation was undertaken. All participants completed the same questionnaire.

Together these were collectively contextualized to fit this study and the Ghanaian scenario. The survey questionnaire instrument's reliability was ensured in diverse ways, namely through clear instructions and the wording of questions. The administration of the questionnaire took the form of face-to-face interviews, including self-administration. The face-to-face interviews were conducted in both the English language and Ghanaian languages namely Ga, Ewe, and Twi. The questionnaire contained standardized instructions, namely "please tick where appropriate." Also, trait sources of error were minimized through interviewing respondents at their convenience. To achieve this, multiple interview appointments were scheduled at one time. The validity of the survey data was attained following Nardi [37]'s guidelines. The validity of the data was obtained from face-to-face interviews. Also, the survey sought an alternative source for confirmation through further in-depth interviews. 
Interviews

The sample for the qualitative phase was selected from that used in the quantitative phase as well as other stakeholders-near-retirees and retirees, utilizing purposive sampling technique. Purposive sampling was used for diverse reasons, including its importance in the selection of participants who had specific characteristics such as sources of information. The 10 participants were divided into three planned interviews based on their convenience (i.e., participants' preference of time and location). The interview themes that emerged were related to the perception of social contact, house location and health outcomes and a host of others, and suggestions for future studies.

Initially, the researcher reminded participants about the aims of the study and that the discussion would be used to suggest future directions. The interviews were designed to gain an understanding focused on the connection between house ownership and health outcomes. In-depth interviews were used in the gathering of data. The interviews were conducted for a period ranging between 60 and $90 \mathrm{~min}$. Prior to the interviews, permission to tape record discussions and informed consent were sought.

Each in-depth interview took the form of a semi-structured interview and was conducted individually in the participant's office or chosen location. The interviews were audio-taped. Face-to-face interviews are endowed with the merit of providing pertinent information while allowing the researcher the opportunity of control over the line of questioning [38].

\subsection{Data Collection}

Institutional Review Board (IRB) approval was attained by the researcher from the University of Ghana. Confidentiality and anonymity were ensured.

A questionnaire was used in the process of data collection in the first phase. The administration of this questionnaire took the form of face-to-face interviews to eliminate the situation of unreturned questionnaires. The main strategies for finding appropriate participants comprised contacting key players in different organizations.

It is worth reiterating the fact that the quantitative study was not anonymous. To prevent it from affecting the results of the study, the participants were informed about information that was to be collected from them and how their identities were going to be protected. This information was included in the study's informed consent form as the best way to explain the nature of the data collection and to assure participants that their privacy was going to be protected.

\subsection{Data Analysis}

Methodological triangulation was deployed to include the combination of methods to understand and explain [39] the relationship between house ownership and health outcomes, as mentioned earlier. The answered questionnaire were cleaned and serialized for easy identification. The survey data were entered into the Statistical Package for Social Science (SPSS) and were analyzed with selected descriptive statistics, namely frequencies, percentages, Chi-square statistics, and Cramer's V test.

Use was made of Pearson Chi-Square statistics to test the following hypotheses: There is no difference in house ownership between age groups; there is a difference in house ownership between age groups, utilizing a 2 tailed test at $5 \%$ level of significance as shown on Table 1 . In the same vein, the data were subjected to Pearson Chi-square statistics and Cramer's V test for purposes of ascertaining the association between house ownership and health outcomes (See Table 2). 
Table 1. Pear Chi-square Test statistics on age and house ownership.

\begin{tabular}{cccc}
\hline & Values & df & Asymp. Sig (2-Sided) \\
\hline Pearson Chi-Square & 120.453 & 6 & 0.000 \\
N of valid Cases & 442 & & \\
\hline \multicolumn{4}{c}{ Source: Field data. }
\end{tabular}

Table 2. Test statistics of house ownership and health outcomes.

\begin{tabular}{cccc}
\hline Tests & Values & Degrees of Freedom & Asymp. Sig. (2-Sided) \\
\hline Pearson Chi-Square & $150.801 \mathrm{a}$ & 10 & 0.000 \\
Cramer's V & 0.750 & 10 & 0.000 \\
N of Valid Cases & 442 & & \\
\hline
\end{tabular}

Source: Field data.

Transcripts from the interviews were subjected to thematic analysis. Thematic analysis entails the process of encoding qualitative as well as textual information. Despite the strict procedural nature of coding and themes that emerged from constant immersion with qualitative data, reference [40] contends that thematic analysis is more exploratory. For the interviews, data analysis was first conducted by the researcher and subsequently by an independent researcher with experience in qualitative data analysis to increase confirmability and dependability. Both researchers ensured dependability by keeping a coding manual, which included original extracts from the interviews and definitions of the emergent themes [41].

A combination of the following analytic strategies was employed in this paper. First, analytic induction, which was related to reaching general explanations. Second, thematic analysis which pertained to the examination of theoretical themes or hypotheses of research through studying particular cases. Finally, narrative analysis was used to search for new themes or issues from the stories told by the research participants about their lives.

In this research, the five major themes identified from the literature review constituted the backbone for analyzing the data collected from fieldwork in Urban Ghana in support of the thematic analysis technique. The analysis process was aided by the application of the framework method in which matrix-based comparisons such as comparative tables were undertaken. The framework table offered detailed analysis of the data within a particular theme. This therefore provided a clearer and deeper understanding of key themes within the context of the study. Efficiency of the thematic analysis carried out was ensured by following a variety of principles in the course of data processing, namely: repetition in search of issues that are commonly repeated by interviewees; and non-repetition in search of issues that were rarely mentioned by the interviewees; similarity and difference in search of similar and different responses among interviewees on a given theme such as the frequency of health resource patronage; metaphors in search of issues that are used as metaphors; transitions in search of issues that link themes and sub-themes together. Theory linkage was also used in the search for linkages or connections to the outcomes of research findings. These were undertaken to ensure the pursuance of the relationship between categories and themes of data, seeking to increase the understanding of the relevant phenomenon. Each of the researchers read the scripts in detail, and then individually coded and categorized data from the same interview. Data from the interviews were coded by the researchers and across the entire interview data, capturing diverse views. Through constant comparison, constant refining resulted in a list of themes (e.g., house acquisition and ownership, house location, social contact and interaction, and health consequences), with their importance determined by frequency, multiplicity of participants' views as well as uniqueness.

Inductive thematic analysis using NVivo 10 software was undertaken [42]. The NVivo software was employed in this study in order to obtain rigor in dealing with such data using six distinct steps. The first step was the creation of a project which comprised all the documents, coding data and related information that assisted in the process of data analysis as well as saving the NVivo project. Second, the 
transcribed audio-recorded interview files were named respectively. The third step entailed working with qualitative data files which entailed the preparation of documents for import, following which the requisite documents that were intended to be analyzed were then imported. The fourth step was related to working with nodes. Nodes store is a place in NVivo for references to code text. Both tree and free nodes were created and used.

Fifth, in data coding, a chunk of data in a project document under a particular node was taken through the highlight of the requisite text using the mouse and pulling the highlighted text to the identified node using the coder. This included finding obvious themes as well as auto-coding. Subsequently, multiple codes were assigned to the same chunk of the text, including going through the same process. The codes formed a pattern. The passage of texts was compared and contrasted for the ways in which they were similar and different. The emergent concepts for example were all health concerns or responses: limited health access etc. Others were the dimension of the use of accessibility of healthcare services - cost, exemption, etc. The final step pertained to going further which encompassed the following: the start of analysis, going further with concepts, categories and themes including narrative and discourse. Memos were used to tell the story of the research by adding descriptions. The knowledge developed from the data was reported.

The outcomes of these activities were recorded in discussion memos. These strategies were integrated into the process of learning from the data. A thematic multi-case analysis was employed, the comparative focus of which was on individual cases as well as the preservation of their uniqueness.

\section{Results}

\subsection{Socio-Demographics}

The study population consisted of 213 males (48.2\%) and 229 females (51.8\%) aged between 18-59 years. Most of the respondents had some level of education and were constituted by the formal sector $(221,50 \%)$ and informal sector workers $(221,50 \%)$ (Table 3). Overall, the highest educational level attained by a near majority of the respondents $(46.4 \%)$ was tertiary education. The no formal education designation is simply indicative of the attainment of non-formal classroom education including those who could not complete primary six. The pre-tertiary category encompasses primary, JHS, SHS, Technical, Commercial, Secretarial, GCE O' Level education. The tertiary category comprised bachelors', post-graduate diploma and master's degrees.

Table 3. Respondent demographics.

\begin{tabular}{cccc}
\hline Variables & Characteristics & Frequency & Percent (\%) \\
\hline \multirow{4}{*}{ Age } & $18-24$ & 21 & 4.8 \\
& $25-29$ & 42 & 9.5 \\
& $30-34$ & 81 & 18.3 \\
& $35-39$ & 58 & 13.1 \\
& $40-44$ & 67 & 15.2 \\
& $45-49$ & 59 & 13.3 \\
\multirow{2}{*}{ Gender } & $50-54$ & 54 & 12.2 \\
& $55-59$ & 60 & 13.6 \\
\hline \multirow{3}{*}{ Educational level } & Male & 213 & 48.2 \\
& Female & 229 & 51.8 \\
\hline \multirow{2}{*}{ Sector of work } & No-formal education & 24 & 5.4 \\
& Pre-tertiary education & 212 & 48.0 \\
& Tertiary & 206 & 46.4 \\
\hline \multirow{2}{*}{$*$} & Formal & 221 & 50 \\
& Informal & 221 & 50 \\
\hline
\end{tabular}

Source: Field data. 


\subsection{Workers' Old Age Oriented Expectations}

Old age expectations in this context comes in two distinct forms, namely the individual level and stated level expectations. Old age expectations are normally oriented towards the kinds of desires that individuals have regarding life in old age, such as access to social amenities including healthcare, financial resources and security, and a host of others. These are referred to as old age entitlements (OAEs) or formal support infrastructure. From Figure 1, more males (50.8\%) than females $(49.2 \%)$ anticipated obtaining financial security in old age, yet more females expected to have a comfortable post-retirement life, access to healthcare, other OAEs and live in their own houses. This may be due to the fact that women live longer than men. The need for housing here indicates a significant expectation. From the interview data, in terms of already acquired houses, the payment of property rate is what remains to be dealt with in post-retirement life; a feature that has been sorted out for people aged $60+$ in Tema. The same applies to late house acquirers.

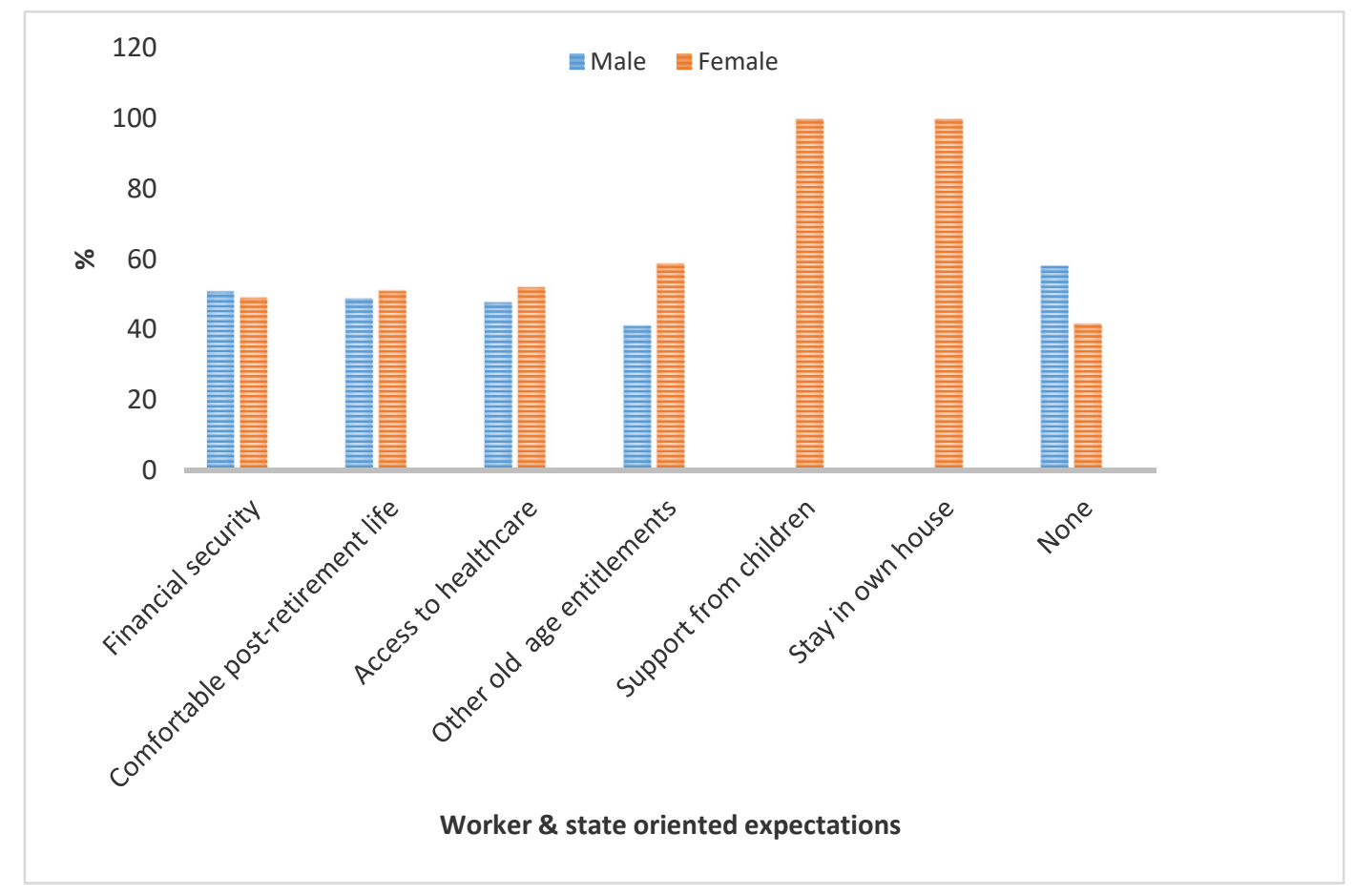

Figure 1. Retirement expectations. Source: Field data.

Access to healthcare, houses and property rebate amongst other factors constitute OAEs. Worldwide OAEs are diverse. These constitute state oriented expectations (Figure 1). However, presently in Ghana, several major OAEs and their associated benefits are summarized below:

- National health insurance (NHI) - the registration and renewal of NHI is free for people aged 70+.

- Property and sewerage rebate, which offers a $30 \%$ property rebate for people aged $60+$ for Tema residents.

Workers' expectations of the state in relation to house acquisition attracts a state response as expressed in the pension system induced housing acquisition and/or ownership. Put differently, the Ghanaian state sought to address workers' housing needs through the pension system. This medium may however have adverse effect(s) on pension funds, yet it is one of the means adopted by the state that is quite apart from state housing schemes.

The quantitative data revealed that the pension system's house acquisition mechanism highlights its in-built benefits namely healthcare, house acquisition, additional income including monthly pension income and lump sum. The former three benefits denote the new components inherent in the new 
three-tier pension scheme and perhaps are not as popularly known as the latter set. To a large extent, whilst some formal sector (31.9\%) and informal sector (68.1\%) workers were not aware of these benefits, more of the former group of workers appeared to have knowledge of these benefits than the latter (Figure 2). This is not surprising due to their level of exposure through seminars, workshops and other sources in favor of the former. This house acquisition mechanism has significance for meeting workers' shelter needs for both pre- and post-retirement life. Essentially, workers and individuals prefer to live in houses of their own, indicating an emphasis on the significance of acquiring a house vis-à-vis life in old age. To some extent, this makes house acquisition synonymous with old age accommodation.

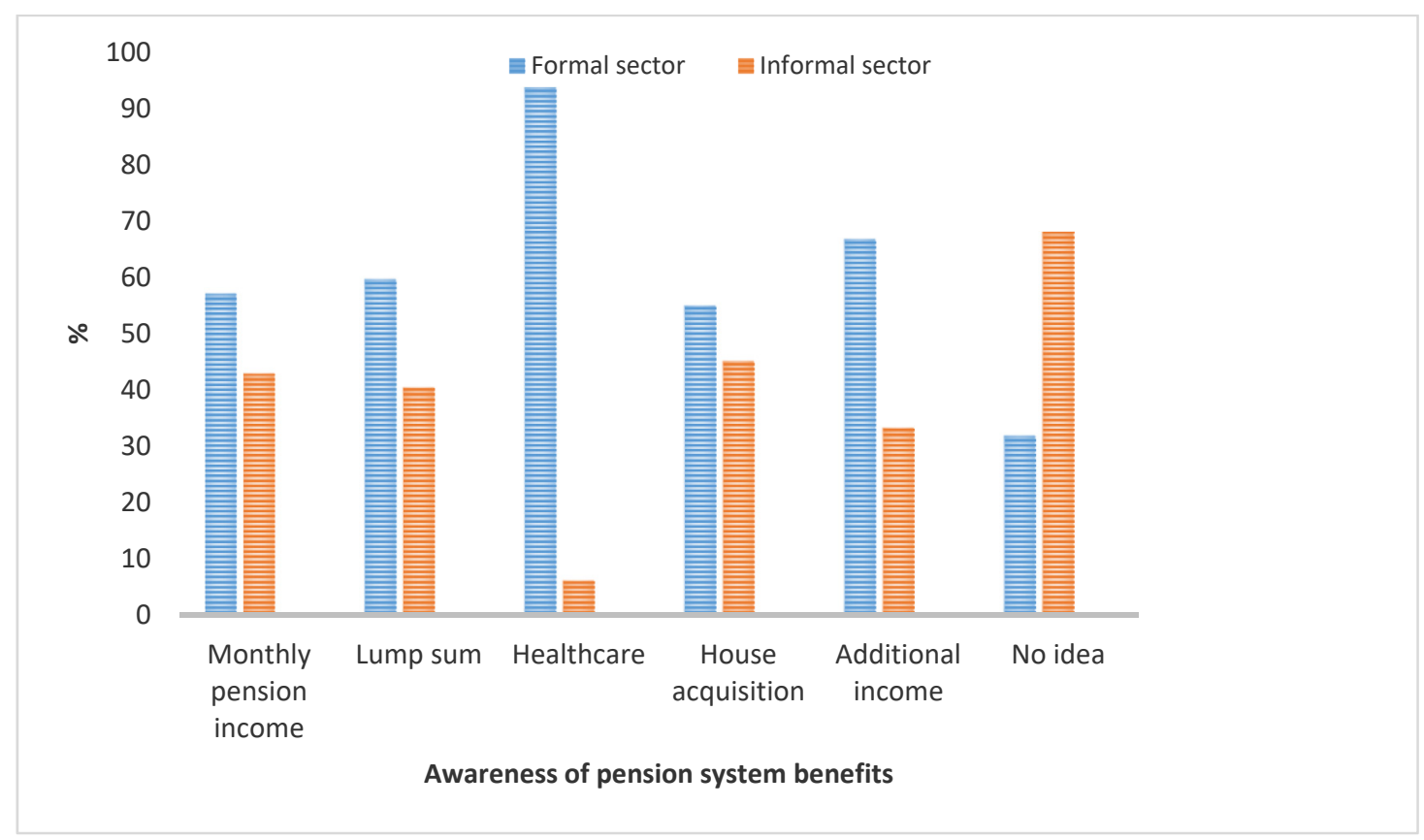

Figure 2. Knowledge of the national pension system's benefits. Source: Field data.

The national pension system accommodates the key variables in this study-housing and healthcare. Whereas the above mentioned system treats both phenomena separately, this study dwells on the linkages between both variables as discussed in the last section.

\subsection{House Ownership}

A cross-tabulation of the results aimed at ascertaining whether there was a difference between age groups in terms of house ownership, indicates that the respondents in the economically active age group 30-39 (62.4\%) and 40-49 (61.3\%) owned houses compared to the near-retirees-50-59 (53.6\%), (See Table 4 for details). However, the latter is comparatively lesser in percentage value compared to the former groups. This may be due to retirement planning orientation and availability of the requisite information.

Table 4. Cross tabulation statistics on age and house ownership.

\begin{tabular}{cccc}
\hline Age Category & Yes & No & Cannot Tell \\
\hline $18-29$ & $26.9 \%$ & $68.7 \%$ & $4.5 \%$ \\
$30-39$ & $62.4 \%$ & $25.5 \%$ & $12.1 \%$ \\
$40-49$ & $61.3 \%$ & $33.9 \%$ & $4.8 \%$ \\
$50-59$ & $53.6 \%$ & $36.4 \%$ & $10 \%$ \\
\hline
\end{tabular}

Source: Field data. 
In addition to the above, in order to emphasize the significance of group divergence on the issue of house ownership, the data were further examined using Pearson Chi-Square statistics where the following hypotheses were tested: There is no difference in house ownership between age groups; there is a difference in house ownership between age groups, utilizing a 2 tailed test at $5 \%$ level of significance. The resulting $p$ value of 0.000 is less than 0.5 (For details, See Table 1 above). This implies by interpretation that there is a difference in house ownership between age groups.

Acquiring a house is undertaken through a variety of means, for instance, state housing schemes, pension system induced medium, including end-of-service benefits (ESBs) for workers with retirement in view as discussed below.

Complementarily, the interview data indicated that living in one's own house/residence mitigates against financial frailty, since rents and reduced pension incomes may contend against each other in terms of expenditure. The interview data revealed that older adults (which in the case of this study encompasses near-retirees-50-59 and 60+ individuals) prefer to live in the same residence at least with their spouses. This is significant, since during retirement, their social network bases dwindle, with the family becoming the key pivot in terms of social relationship consolidation and the attendant benefits thereof. These have been depicted in the following statements:

I have acquired an apartment. I also have a house so that when I retire, I don't have to struggle with issues of accommodation. This, I learnt from my father. It will make life easy for me (Near-retired male).

I have a 2 bedroom house that I intend to live in, when I finally retire (Near-retired female).

I acquired a house long before I retired about 10 years ago. I live in it with my children. At least, I have a roof over my head (Retired female).

I live in my own house with my wife and children. Now that I have retired, I have a sound mind because of this property. If the rest of my children marry, the family size will only reduce but it still will remain intact in this house (Retired male).

My late husband's organization made him an offer regarding the purchase of the residence we were occupying. He discussed the issue with me and I encouraged him to purchase the apartment. He rather told me that he intended to build a house in his hometown in another region other than our region of residence - the Volta Region of Ghana. I vehemently detested that. As a result, I threatened him that if he does not buy the house on offer for us to stay in and he goes building in his hometown, when he retires, my children and I will not follow him to his hometown. He will go alone. You still have the choice of purchasing the property, where we have spent most of our adult lives, I said. However, he did not mind me. He rather continued with his diabolical plan of building elsewhere. A few years after that he retired, the Company's Estate Unit notified him to vacate the residential premises. So, we moved bags and baggage out of the flat. He decided that we go to the village. I blatantly refused. Rather, I reminded him of what I told him earlier. It became a whole argument that brought in other people to intervene. But I did not budge. He packed off to the village. My five children and I rented a house here in Tema and relocated there. He on the other hand, got to the village alright but alone without the children and me. Later we heard that his health condition took a down turn with hypertension and diabetes. With time, his health deteriorated and he died as a result of that, just after two years of retirement (Retired female).

All the quotes above emphasis the role of housing and its significance in old age. Although the quotes do not dwell on community housing for older adults, they outline an age friendly environment, particularly in the last three statements. This has become essential in an era of increasing nucleation of the family. It also has implications for conducive institutional home contexts, although presently, it is in its nascent phase in Ghana. Also, it draws a connection between the location of houses and the fragility of family units. 


\subsection{Provision of End-of-Service Benefits}

The notion of ESBs clearly shows that more often than not, workers' retirement plans are supplemented by organizations and/or employers. It is worth noting that some corporate organizations for example Tema Development Corporation (TDC) and Social Security and National Insurance Trust (SSNIT) contribute towards workers' retirement plans diversely, especially through ESBs. Summarized below are the constituent elements of ESBs for workers based on the interview data.

- The core constituents of TDC's ESB system include medical care and a housing scheme that comprises plots of land and houses.

- Workers of SSNIT also enjoy employers' retirement benefits in the form of medical care till death, house provision or housing loan.

Table 5 shows that some corporate organizations are sensitive towards workers' plight in terms of life in old age expressed in the form of ESB. These ESB components espouse two significant components namely healthcare and houses, both of which have implications for the creation of an age friendly environment.

Table 5. Employers' benefits as supplementary retirement portfolios.

\begin{tabular}{ccc}
\hline \multirow{2}{*}{ Benefits } & \multicolumn{2}{c}{ Organizations } \\
\cline { 2 - 3 } & SSNIT & TDC \\
\hline House & $\bullet$ & $\bullet$ \\
Housing loans & $\bullet$ & $\bullet$ \\
Plots of land & & $\bullet$ \\
\hline
\end{tabular}

Source: Field data.

\subsection{Linkage between House Ownership and Health Outcomes}

The survey data was subjected to Pearson Chi-square statistics and Cramer's V test in order to ascertain the association between house ownership and health outcomes (Table 2). The Cramer's $\mathrm{V}=0.750$ outcome indicates a strong association between the two variables. This has implications for the relationship between house ownership and health conditions.

The Cramer's V Test value above is a reflection of the fact that housing correlates positively with healthcare, an indication that an age friendly community is imperative, particularly for persons of older ages. Indeed, house ownership and a sound housing system provides security for individuals, especially older people in terms of access to shelter or its related needs' satisfaction or resolution. Also, house ownership ensures a sound mind, with implications for improvement in older adults' physical and mental health.

\section{Discussion}

Old age expectations come in two distinct forms: namely individual and state level expectations, as depicted on Figure 1. Old age oriented expectations of individual workers comprise the acquisition and ownership of houses and the attendant health outcomes. Such a house when acquired may be known as what Dovie et al. [5] termed 'retrilocal residence'. This house may not be the same as an aging community per se. The latter may be possible if the state links the pension system induced housing purchase mechanism to the affordable schemes, e.g., the affordable housing system. Whereas individual level old age expectations are geared towards owning a house, the state oriented ones focus on healthcare expressed in NHIS. The state level expectations and its attendant provisions denote OAEs as mentioned earlier. Workers' house acquisition and ownership bids were also boosted by ESB packages from employers and/or organizations. The existing OAEs in Ghana include healthcare expressed in NHI and property rebate. These form the state dimension of care, which are supposed to 
create conducive age friendly environments or contexts for older adults. However, these are inadequate and need to be scaled up appreciably for older people's sustenance.

Collectively, these depict house acquisition and ownership streams which have healthcare linkages, since both variables have significant health outcomes. Workers' state level expectations pertaining to state support in house acquisition was addressed in the national pension system dimension of house acquisition (see reference [5] for details).

The results also show in Table 4 that comparatively more economically active workers own houses than the near-retirees. This may be due to increased inclinations towards home ownership on the former's part, high rates of investments among younger generations, the fact that retirement is about preparing for the future from today, as well as increased availability and accessibility of retirement planning information $[6,27,43,44]$. Statistically, housing was observed to positively correlate with health outcomes, with negative repercussions for health conditions. This alludes to the fact that age friendly environments are key. Significantly, there is a difference between house acquisition and ownership, and age groups. This was attested to by a $p$ value of 0.000 (see Table 2 above for details). Mostly, the houses were acquired through state housing schemes, pension system induced mechanism as well as ESBs.

This creates an enabling environment for workers to better plan towards retirement in a more organized manner, particularly with respect to housing arrangements. It stresses the complex factors or contexts that shape preparations towards later life, addressing the individual's attempt to forestall uncertainty with regard to the future [44,45]. Finally, the notion of ESB suggests that workers' preparations for retirement are supplemented to some extent by employers' designated occupational benefits, especially in the formal sector. The latter confirms what reference [17] found. As indicated earlier, Act 766 [46] mandates that funds accrued in tiers two and three can be used to acquire a primary residence. In confirmation, Barrientos [47] indicates that using retirement savings and pensions have been pursued for a range of merit expenditures namely health, housing and education.

Living in one's own houses to a great extent guards against financial frailty, alongside the preferences for living with life partners. The essence of this is made viable in the proffering of social contacts and interactions, particularly because retirees' social networks relatively decrease, especially those of men. Social contact, social interaction and house/residential location are the three elements of age friendly communities in the study. Age friendly communities and positive outcome variables also have implications for retirement communities. An age friendly environment/community therefore assists the firming up of relationships as people age. This implies that love and care in old age illuminate older people's lives, affecting their health and well-being. The health of human populations is shaped by certain 'social determinants' such as social ties, poverty and low education [48].

This is because social relations and interaction irrespective of the form they take may need to be relatively regular. This experience may vary based on the number of children and grandchildren, including financial and other resources an individual may possess in readiness for post-retirement life. The situation may be different for people who are childless or have lost their children due to travel to other countries and regions, and death. Social relations contribute to the phenomenon of age friendly communities, barring loneliness and ostracization of the older person. These two-loneliness and ostracization fester concerns that can contribute to ailing health conditions and related healthcare service solicitation.

However, house acquisition and ownership are better undertaken in an age friendly environment in the purview of increased nucleation of the family, as well as the weakening of the extended family system $[6,49,50]$. It has further been argued that there are people who have never joined a pension system, neither have they possessed sufficient resources in aid of preparation towards a formal pension for their old age [17]. This notwithstanding, houses are acquired through ESBs individually, including via the medium of gifts. The connection between housing and healthcare, obtainable from the qualitative data has dwelt on the repertoire of location, families; acceptance of location, and social support at designated location(s). This type of environment is also underpinned by healthcare 
dynamics. Two comorbidities presented in this paper are hypertension and diabetes, both of which are non-communicable diseases (NCDs) [51]. Perceptions about situational and environmental factors for example proximity, familiarity as well as urban features contribute to the way people act or react to house and health matters.

Spending pension incomes on housing issues in old age is not age friendly, since it saps away financial resources that could be conserved and used for other exigencies proffered by NCDs and other related diseases in lieu of a sound solicitation of healthcare services and the related outcomes.

'Sound mind' as mentioned in one of the quotes in the previous section is here associated with mental health, since healthcare emphasizes mental health. For that matter, an age friendly housing environment has health and well-being outcomes, as it puts the minds of (older) people to rest, a sign that an individual has one less thing to worry about. Stated differently, worrying about the lack of a house or a residential facility including the need to pay rent at old age has healthcare repercussions, as this may be a precursor to NCDs such as hypertension, diabetes, among others. Previous studies, see Kpessa [52] for example, show that NCDs do not constitute a core component of Ghana's healthcare provision as a formal social support infrastructure. For instance, van der Geest [29] found that "The NHIS prescribes the same basic healthcare without taking into consideration the tertiary healthcare needs of older people especially in the area of NCDs including retention of urine, incontinence, prostrate and colon cancers" (p. 11). Pensioners' association membership nationwide has benefits which encompass participation in the pensioners' medical scheme, a complement to NHIS, among others [21].

Thus far, the discussion has focused on the housing system at the individual level. At the group level, old age homes or retirement homes may serve as an alternative to the former, which is not very well entrenched in lower and middle income countries including Ghana, yet is worth mentioning here because although it seems to be a 'rejected' concept on cultural grounds [29], it is worth taking into consideration.

As such, age friendly living environment regimes for older adults could entail adult day care or retirement communities, regardless of whatever the form is, private or governmental, or the amount of space or conditions provided for older adults. There is also the hospice dimension that must be accounted for, including end-of-life care, call practices, and the involvement of home care agencies. Collectively, these offer medical care, physical and occupational therapy, psychosocial support and home care. It is worth reiterating the fact that retirement communities should be structured around independent living, assisted living, skilled nursing homes equipped to offer and perform activities of daily living (such as mobility, dressing, bathing, use of the toilet, eating) and hospices [49].

This confirms Daly et al. [53]'s assertion that adjustment to aging may be reached by balancing personal experiences, self-standards, personal aims, core motivations and values with external influences. Such facilities and their tenants might require supportive services because they may have some combination of age-based chronic illnesses, disabilities, and limited social supports, in addition to having modest incomes [4].

However, Sarpong [54] contends that:

I have always considered it is degrading in industrialized societies; that old people are put in old people's homes where they are visited by their children from time to time. We must desist from creating or introducing such life's dead ends into Ghanaian life. For me, the day we adopt such a culturally humiliating system will be gloomy one indeed. Let us continue to keep the aged in their homes with their children and grandchildren (p. 19).

The above statement implies that in the 1980s, when Sarpong made this observation, most people lived predominantly in the rural areas with their extended families. But, with the emergence of social change, people have found themselves in urban centers due to rural-urban migration and the search for white collar jobs, and have grown old in these urban locations. Most of these people may not return to the rural centers. In assessing the connection between living in institutional homes and attendant 
adjustment, Sarpong [54] intimated that institutional homes have never been a part of the Ghanaian culture. Instead, institutional homes are a feature of a foreign culture that has been adopted due mostly to the weakening of the extended family support system.

Wealth accumulation, gender and environmental inequality have occurred for decades or more as a result of patriarchal structures, controlled by the few in power. The multiple indirect ways through which these concepts have evolved to function in modern day societies further complicate attempts to resolve them and transform the social and natural world towards a more sustainable paradigm. By partly relying on queer ecology, this paper opens the space for uncovering some hidden mechanisms of asserting power and patriarchal methods of domination in family relationships. Patriarchy and gender inequality have a substantial impact on power relations and control of resources [55]. The retiree depicted as being dead in the longest and last qualitative quote in the study exhibited male power and the patriarchal tendency of being the person with the financial resources for house purchase, and did not show a need to pay attention to the wife's admonition by deciding to build in a remote area in Ghana. The wife on the other hand, was unequal with the husband in terms of access to and availability of financial resources. Thus, his interest prevailed. Such a factor must be taken into account when planning for an age friendly environment at the individual level.

House or accommodation arrangement in the context of this paper is a reflection of a risky situation if it is not properly addressed, taking into account relocational attributes and outcomes. On the one hand, such arrangements may yield certainties such as having close family relations relocate with the retiree across boundaries with them to their preferred destinations and live happily thereafter. This may depict the ideal situation though. On the other hand, relocational sojourns are not always undertaken together with the relocators in question, as this study depicts. This is a recipe for an aging risk and uncertainty ramifications, and could foster future oriented aging spaces that lack considerations of future housing or accommodation security vis-à-vis the implications for health conditions and/or outcomes.

\section{Conclusions}

Among several other factors (namely finance, disrespect, and loneliness), accommodation and health are some of the major challenges of retirement. Availability and affordability of houses have implications for the outcomes of health conditions. House acquisition and ownership can potentially improve the overall physical and mental health and wellbeing of individuals. House ownership has the propensity to facilitate healthy living. It shapes health outcomes in two distinct ways when carefully considered. First, it does so through social contacts and social interaction in neighborhoods. These in turn serve as a buffer against loneliness. The notion that loneliness is likely to cause the death of inmates of institutional homes may find expression in less social engagement, which Shah et al. [56] argues may result in insufficient attention provision that may be responded to with some adverse reactions, perhaps even violence. Second, in the context of this paper, an age friendly community finds expression in an environment in which social contact and social interaction as well as the location of houses are notable variables for major consideration.

Therefore, this paper catalogues the outline of workers' retirement aspirations, namely living in one's own house and being surrounded by family relations as shown on Figure 1, as well as the actualization of the same. Yet, the ability to actualize these aspirations is affected by the locations of housing facilities, including the associated social dynamics and physical well-being implications for health outcomes. It is concluded that lackadaisical housing arrangements have negative consequences for health outcomes as observed in the paper, gleaned from the qualitative data, notwithstanding the fact that house acquisition and ownership, and health outcomes are positively correlated.

Funding: This research was funded by [the University of Ghana's Carnegie African Next Generation of Academics Research Grant], grant number [UGFD/cc/061/2014-2015].

Conflicts of Interest: The authors declare no conflicts of interest. 


\section{References}

1. De-Graft Aikins, A.; Apt, N.A. Aging in Ghana: Setting priorities for research, intervention and policy. Ghana Stud. J. 2016, 19, 35-45. [CrossRef]

2. GSS. 2010 Population and Housing Census Summary Report of Final Results. 2010. Available online: http://statsghana.gov.gh/docfiles/2010phc/Census2010_Summary_report_of_final_results.pdf (accessed on 23 November 2015).

3. GSS. 2010 Population and Housing Census: National Analytical Report; GSS: Accra, Ghana, 2013.

4. Obiri-Yeboah, D.A.; Obiri-Yeboah, H. Ghana's pension reform in perspective: Can the pension benefits provide a house a real need of the retiree? Eur. J. Bus. Manag. 2014, 6, 121-133.

5. Dovie, D.A.; Ayimey, I.R.; Adodo-Samani, P. Pension policy dimension to Ghanaian workers' housing needs provision. Soc. Novas Mod. 2018, 35, 30-56. [CrossRef]

6. Dovie, D.A. Systematic preparation process and resource mobilisation towards postretirement life in urban Ghana: An exploration. Ghana Soc. Sci. J. 2018, 15, 64-97.

7. Moons, N. The Right to Housing Laws and Society, 1st ed.; Routledge: New York, NY, USA, 2018.

8. Berger, A. Encyclopedic Dictionary of Roman Law; American Philosophical Society: Philadelphia, PA, USA, 1980, ISBN 978-0-87169-432-4.

9. Government of Ghana. Constitution of Republic of Ghana; National Commission on Civic Education: Accra, Ghana, 1992.

10. Government of Ghana. Labour Act, 2003: Arrangement of Sections. 2003. Available online: http: //www.nlcghana.org/nlc/privatecontent/document/LABOURACT2003.pdf (accessed on 15 February 2016).

11. Hodges, J.; Baah, A. National Labour Law Profile: Ghana. 2019. Available online: http://www.ilo.org/ ifpdial/information-resources/national-labour-law-profiles/WCMS_158898/lang--en/index.htm (accessed on 13 April 2019).

12. Diamond, R. What Does Economic Evidence Tell Us about the Effects of Rent Control? 2018. Available online: https://www.brookings.edu/research/what-does-economic-evidence-tell-us-about-the-effects-ofrent-control/ (accessed on 15 April 2019).

13. Diamond, R.; McQuadey, T.; Qian, F. The effects of Rent Control Expansion on Tenants, Landlords, and Inequality: Evidence from San Francisco. 2017. Available online: https://cepr.org/sites/default/files/McQuade, \%20Tim\%20DMQ_Paris.pdf (accessed on 15 April 2019).

14. Government of Ghana. National Housing Policy. 2015. Available online: https://www.gredaghana.org/ policy/National\%20Housing\%20Policy.pdf (accessed on 17 April 2019).

15. Lusardi, A.; Mitchell, O.S. Older Adult Debt and Financial Frailty; Research Paper No. 2013-291; Michigan Retirement Research Center, University of Michigan: Ann Arbor, MI, USA; Available online: https: //mrdrc.isr.umich.edu/publications/papers/pdf/wp291.pdf (accessed on 6 March 2019).

16. Chesser, A.K.; Keene Woods, N.; Smothers, K.; Rogers, N. Health literacy and older adults: A systematic review. Gerontol. Geriatr. Med. 2016, 2. [CrossRef] [PubMed]

17. Wolf, M.; Gazmararian, J.A.; Baker, D.W. Health literacy and functional health status among older adults. Arch. Intern. Med. 2015, 165, 1946-1952. [CrossRef] [PubMed]

18. Dury, S.; Dierckc, E.; van der Vorst, A.; van der Elst, M.; Fret, B.; Duppen, D.; Hoeyberghs, L.; De Roeck, E.; Lambotte, D.; Smetcoren, A.-S.; et al. Detecting frail, older adults and identifying their strengths: Results of a mixed-methods study. BMC Public Health 2018, 18, 191. [CrossRef] [PubMed]

19. Hardy, S.E.; Concato, J.; Gill, T.M. Stressful life events among community-living older persons. J. Gen. Intern. Med. 2002, 17, 841-847. [CrossRef]

20. Apt, N.A. Ageing and the Changing Role of the Family and the Community: An African Perspective. Int. Soc. Secur. Rev. 2002, 55, 39-47. [CrossRef]

21. Dovie, D.A. Leveraging healthcare opportunities for improved access among Ghanaian retirees: The case of active ageing. J. Soc. Sci. 2018, 7, 92. [CrossRef]

22. Sharma, S.; Mueller, C.; Stewart, R.; Veronese, N.; Vancampfort, D.; Koyanagi, A.; Lamb, S.E.; Perera, G.; Stubbs, B. Predictors of falls and fractures leading to hospitalization in people with dementia: A representative cohort study. J. Am. Med. Dir. Assoc. 2018, 19, 607-612. [CrossRef] [PubMed]

23. Ayete-Nyampong, S. Ageing in Contemporary Ghana; Paper and Ink Media: Accra, Ghana, 2015. 
24. Zheng, C.; Yuetao, S.; Jia, Y.; Jintang, W. Differential development strategies of aged care support and community services in China, Japan and Australia. J. Clin. Gerontol. 2014, 5, 36-41. [CrossRef]

25. Barrow, G.M. Ageing, the Individual and Society, 3rd ed.; West Publishing for Company: New York, NY, USA, 1986.

26. Moody, H.R. Ageing: Concepts and Controversies, 6th ed.; Fine Forge Press: Los Angeles, CA, USA, 2010.

27. Dovie, D.A. Financial literacy in an African society: An essential tool for retirement planning. Contemp. J. Afr. Stud. 2018, 5, 26-59.

28. Agrawal, G.; Arokiasamy, P. Morbidity prevalence and healthcare utilization among older adults in India. J. Appl. Gerontol. 2010, 29, 155-179. [CrossRef]

29. Van der Geest, S. Will families in Ghana continue to care for older people? Logic and contradiction in policy. In Ageing in Sub-Saharan Africa: Spaces and Practices of Care; Hoffman, J., Pype, K., Eds.; Policy Press: London, UK, 2016; pp. 21-42.

30. Bloom, D.E.; Chatterji, S.; Kowal, P.; Lloyd-Sherlock, P.; Mckee, M.; Rechel, B.; Smith, J.P. Microeconomic implications of population aging and selected policy responses. Lancet 2015, 385, 649-657. [CrossRef]

31. Chen, L.K. Towards elder-friendly outpatient services. J. Chin. Med Assoc. 2012, 75, 617-618. [CrossRef]

32. Lukes, S. Power. A Radical View, 1st ed.; MacMillan Education: London, UK, 2005; p. 1.

33. Barnett, M.; Duvall, R. Power in international politics. Int. Org. 2005, 59, 39-75. [CrossRef]

34. Moore, D.R.; McCabe, G.P. Introduction to the Practice of Statistics, 2nd ed.; W.H. Freeman and Company: New York, NY, USA, 1993.

35. Ghana Statistical Service. 2010 Population and Housing Census: District Analytical Report-Accra Metropolitan. 2012. Available online: http://www.statsghana.gov.gh/gssmain/storage/img/marqueeupdater/ Census2010_Summary_report_of_final_results.pdf (accessed on 1 February 2016).

36. Perneger, T.V.; Courvoisier, D.S.; Hudelson, P.M.; Gayet-Ageron, A. Sample size for pre-test of questionnaires. Qual. Life Res 2015, 2, 147-151. [CrossRef]

37. Nardi, P. Doing Survey Research: A Guide to Quantitative Methods; Pearson: Boston, MA, USA, 2006.

38. Neuman, W.L. Basics of Social Research: Qualitative and Quantitative Approaches; Pearson: Boston, MA, USA, 2004.

39. Greenstein, R.; Roberts, B.; Sitas, A. Research Methods Training Manual. Compiled and Edited by Ran Greenstein. 2003. Available online: https://www.academia.edu/3198713/Research_Methods_Training Manual (accessed on 14 March 2019).

40. Joffe, H.; Yardley, L. Content and thematic analysis. In Research Methods for Clinical and Health Psychology; Marks, D.F., Yardley, L., Eds.; SAGE Publications: Thousand Oaks, CA, USA, 2004; pp. 56-68.

41. Johnstone, P.L. Reflexivity and transparency in weighting up triangulating and contradictory evidence in mixed methods organisational research. In Proceedings of the 2nd Qualitative Research as Interpretive Practice Conference; Charles, S., Ed.; University of Michigan Medical Center Journal: Ann Arbor, MI, USA, 2006.

42. Bazeley, P.; Jackson, K. Qualitative Data Analysis with Nvivo, 2nd ed.; SAGE Publications: Thousand Oaks, CA, USA, 2014.

43. Dovie, D.A. The influence of MIPAA in formal support infrastructure development for the Ghanaian elderly. Int. J. Ageing Dev. Ctries. 2019, 3, 47-59.

44. Dovie, D.A. Utilization of Digital Literacy in Retirement Planning Among Ghanaian Formal and Informal Sector Workers. Interações Soc. Novas Mod. 2018, 34, 113-140. [CrossRef]

45. Holzmann, R.; Stiglitz, J. Introduction. In Toward Sustainable Pension Systems in the 21st Century: New Ideas about Old Age Security; Holzmann, R., Stiglitz, J., Fox, L., James, E., Orszag, P., Eds.; The World Bank: Washington, DC, USA, 2001; pp. 1-16.

46. Government of Ghana. National Pension Act, 2008-Act 766; National Pensions Regulatory Authority: Accra, Ghana, 2008.

47. Barrientos, A. Comparing pension schemes in Chile, Singapore, Brazil and South Africa. In Living longer: Ageing, Development and Social Protection; Lloyd-Sherlock, P., Ed.; Zed Books: London, UK, 2004; pp. 122-140.

48. Frank, A. The individual in ageing Germany: How the self-employed plan for their old age. In Population Ageing from a Lifecourse Perspective: Critical \& International Approaches; Komp, K., Johanson, S., Eds.; Policy Press: Bristol, UK, 2015.

49. Dovie, D.A. The status of older adult care in contemporary Ghana: A profile of some emerging issues. Front. Sociol. 2019, 4, 25. [CrossRef] 
50. Aboderin, I. International Support and Old Age in Africa; Transaction Publishers: London, UK, 2006.

51. Olenick, M.; Flowers, M.; Muñecas, T.; Maltsev, T. Positive and negative factors that influence health care faculty intent to engage in interprofessional education (IPE). Healthcare 2019, 7, 29. [CrossRef]

52. Kpessa, W.M. The politics of retirement Income security policy in Ghana: Historical trajectories and transformative capabilities. Afr. J. Political Sci. Int. Relat. 2011, 5, 92-102.

53. Daly, T.; Armstrong, P.; Lowndes, R. Liminality in Ontario's long-term care Facilities: Private companions' care work in the space "betwixt and between". Compet. Chang. 2015, 19, 246-263. [CrossRef] [PubMed]

54. Sarpong, P.K. Ageing and tradition. In Ageing and Social Change: A Ghanaian Perspective; Opare-Abetia, J., Ed.; Institute of Adult Education: Legon, Ghana, 1983; pp. 13-20.

55. Suliman, N.N. The Intertwined Relationship between Power and Patriarchy: Examples from Resource Extractive Industries. Societies 2019, 9, 14. [CrossRef]

56. Shah, A.K.; Mullainathan, S.; Shafir, E. Some consequences of having too little. Science 2012, 338, $682-685$. [CrossRef]

(C) 2019 by the author. Licensee MDPI, Basel, Switzerland. This article is an open access article distributed under the terms and conditions of the Creative Commons Attribution (CC BY) license (http://creativecommons.org/licenses/by/4.0/). 